\title{
Hipnose e Psicologia Clínica: Retomando a História Não Contada
}

\author{
Hypnosis and Clinical Psychology: Bringing Back the Untold History \\ Maurício da Silva Neubern* \\ Centro Universitário de Brasília, Brasília, Brasil
}

\begin{abstract}
Resumo
O presente artigo aponta várias relações entre a psicologia clínica e a hipnose, destacando que boa parte destas permaneceram e ainda se encontram pouco conhecidas da grande maioria dos psicólogos clínicos. Por um lado, visa destacar acontecimentos históricos dessa relação que, apesar da pertinência, foram marginalizados e esquecidos, o que remete, sobretudo, às práticas institucionais vigentes neste ramo da psicologia. Ao mesmo tempo, o artigo busca destacar brevemente que a reflexão sobre a hipnose pode levar a psicologia clínica a reformulações epistemológicas, institucionais e práticas da mais alta relevância, principalmente em termos de colocá-la em sintonia com importantes discussões atuais do panorama científico. Por fim, ressalta que, pelas próprias características da hipnose enquanto tema de reflexão e estudo, ela incita radicalmente a uma tomada de rumo na direção da construção de um conhecimento onde seja possível o auto-conhecimento, rompendo com as tradições modernas do pensamento científico.

Palavras-Chave: Hipnose; psicologia clínica; história; epistemologia.
\end{abstract}

\begin{abstract}
The present article points out various relations between clinic psychology and hypnosis, highlighting that a great part of both has remained well unknown by the great majority of clinic psychologists. On one hand, this article aims at historical outcomes of this relation, which despite having been put aside and forgotten, takes us back to the institutional practices taking place in this field of psychology. On the other hand, it intends to briefly bring about that the reflection over hypnosis might present clinic psychology with epistemological, institutional and practical reforms of the highest relevance, especially in terms of making hypnosis function in sync with important present discussions on the scientific scenery. Finally, this article states that for its own characteristics as a subject of study and reflection, hypnosis radically incites the building up of some knowledge where self-actualization is made possible, which breaks up with the modern tradition of scientific thinking. Keywords: Hypnosis; clinic psychology; history; epistemology.
\end{abstract}

A perspectiva de unificar clínica e ciência trouxe um problema considerável para a psicologia clínica: não seria possível efetivar um acesso privilegiado e único ao real, já que esse ramo da psicologia se encontrava dividido em diversas escolas. Como as exigências do paradigma dominante rezavam o acesso a uma realidade única (Demo, 1997; Morin, 1991; Santos, 1987) tal diversidade colocava a psicologia clínica numa posição incômoda já que não havia meios que pudessem garantir a hegemonia de uma escola sobre as outras. Não lhe havia sido possível a fabricação de um contexto como o laboratório, em que os pareceres distintos e contrários deveriam ser calados diante das provas experimentais (Neubern, 2004; Stengers, 1995). Tal quadro trouxe uma contradição incômoda, pois enquanto a psicologia clínica ganhou espaços sociais e reconhecimento científico, ela jamais pôde atingir, como não o puderam as ciências humanas e sociais, o status da confiabilidade científica das ciências duras, permanecendo a meio caminho de um reconhecimento integral (Neubern, 2003). As conseqüências desse mal estar podem ser compreendidas sob duas dimensões altamente integradas. Por um lado, as noções dominantes do projeto

\footnotetext{
* Endereço para correspondência: SQS 411, BL C, apto. 101, Brasília, DF, 70 277-030. Fone: 61346 4838. E-mail: mneubern@hotmail.com
}

científico foram adotadas de modo particular pelas diferentes escolas, que lhe conferiram uma compreensão própria e continuaram alimentando as rivalidades entre si. $\mathrm{O}$ isomorfismo, a tendência universalista e a ênfase no patológico consistiram em noções constantes em praticamente todas escolas de inspiração moderna (Gergen, 1996; Neubern, 2001).

Mas, ao mesmo tempo, como essa pretensão de acesso isomórfico ao real mantinha-se questionável, a autoridade dos mestres fundadores ganhou relevo cada vez maior, o que conferiu grande influência à dimensão institucional. É justamente nesse ponto que o tema da hipnose assume uma considerável importância, pois toma para si um papel de denúncia das contradições e fragilidades existentes na tentativa de uma psicologia clínica enfim científica (Chertok \& Stengers, 1999; Stengers, 2001). Associando-se a noções epistemológicas marginais como a influência (ao invés da neutralidade), o passageiro (ao invés do definitivo), a criação (ao invés do fato) e o ilusório (ao invés da essência), a hipnose se tornou um objeto de estudo ameaçador capaz de colocar em risco os já comprometidos alicerces que os psicólogos começavam a construir em sua pretensão de ciência. Em termos de instituição e práticas sociais, essa denúncia também mostrou que, sob bases precárias, muitos acontecimentos históricos foram negados ou obscurecidos em nome de um conhecimento científico que integralmente jamais 
foi atingido. Em outras palavras, em nome da própria razão foi preciso que muitos argumentos fossem evitados, uma vez que esses poderiam levar a incisivos questionamentos sobre a coerência dessa mesma razão.

Sendo assim, o objetivo deste artigo é, de início, o de destacar criticamente alguns acontecimentos históricos ligados à relação entre hipnose e psicologia clínica que poderiam levar a reflexões pertinentes sobre essa ciência, mas que foram estigmatizados ou jogados ao esquecimento. Tratam-se especificamente de obras e concepções de certos autores (Bernheim, 1891/1995; Bertrand, 1823 citado em Carroy, 1991; Delboeuf, 1890/1993) que, apesar da relevância clínica e teórica, não ganharam espaço e reconhecimento históricos, como não puderam impedir a construção dos mais diversos preconceitos sobre o tema. Uma vez que levanta essa dimensão esquecida, o artigo também buscará destacar brevemente a pertinência da hipnose como um tema que poderá trazer para a psicologia clínica reformulações fundamentais em termos de práticas institucionais e princípios epistemológicos. Nesse sentido, as reflexões levantadas pela hipnose não só colocam a psicologia clínica em sintonia com as discussões recentes sobre crises de paradigmas na ciência (Demo, 1997; Morin, 1991; Santos, 1987, 2000; Stengers, 1995), como ressaltam que sua relevância como tema de estudo é bastante atual (Borc-Jacobsen \& Dufresne, 2001; Chertok \& Stengers, 1999; Melchior, 1998; Neubern, 2004; Stengers, 2001; Zeig, 1985/1997). Deve-se fazer aqui uma pequena ressalva em função da ênfase conferida à psicanálise de Freud (Salomão, 1996), como uma das principais origens da psicologia clínica. Embora seja possível conceber outras origens dessa disciplina, como Witmer (Schultz \& Schultz, 1969/1981)e Lagache (Levy, 1997), preferiu-se manter a psicanálise como um dos focos centrais da reflexão devido à sua relação histórica com a hipnose e sua influência ainda bastante presente, difundida e atual em diversos contextos e instituições da prática clínica de diferentes escolas ${ }^{1}$.

\section{O Golpe de Força}

A relação entre hipnose e psicologia clínica pode ser compreendida como um processo que se iniciou no entusiasmo e culminou no ostracismo. Essa trajetória, a bem dizer abrupta, pode ser reconhecida em Freud sem maiores dificuldades, pois o método inicialmente eleito por ele para a cura dos doentes nervosos (Freud, 1888-1892/1996a), ao longo de seu trabalho, passou a ser considerado como algo oposto e até indesejável à consecução de um conhecimento confiável e efetivo em termos de terapia e ciência (1905/ 1996b, 1917/1996d). Os impactos desse processo para o reconhecimento da hipnose em termos clínicos e epistemológicos foram drásticos em diversos sentidos (Neubern, 2004). Por um lado, ela se tornou uma espécie de tema maldito, com a qual a psicologia clínica só poderia

\footnotetext{
${ }^{1}$ Dito de outro modo, mesmo que possa ser questionável por várias razões, assume-se no presente artigo a psicanálise como origem inicial da psicologia clínica moderna.
}

reconhecer parentesco nos livros de história. Não é sem razões que as não muito numerosas referências que lhe são conferidas (Figueiredo, 1992; Marx \& Hillix, 1963/ 1978; Schultz \& Schultz, 1969/1981) a situam como um passado longínquo e pré-científico, como um tema já superado que praticamente não encontra espaço nas escolas dominantes e discussões atuais. Contudo, o estigma da maldição também passou a incidir sobre a hipnose em termos de abordagem e técnica, situando-a como técnica ineficaz e superficial que jamais atingiria a causa dos problemas, permitindo a substituição de sintomas, como um procedimento caracterizado pela submissão ao terapeuta, como um processo vicioso e que poderia induzir a condutas perigosas (Melchior, 1998; Yapko, 1992). Enfim, além dos riscos com as quais estaria implicada, a hipnose não teria nada a acrescentar diante da diversidade de escolas e técnicas desenvolvidas após sua derrocada.

No entanto, o que muitas vezes passa desapercebido nas discussões sobre a ciência relacionada a temas complexos como esse é que além das certezas freqüentemente existem as contradições que são evitadas e escondidas para que essas mesmas certezas não sejam ameaçadas. Tal é o caso da relação de Freud (1917/1996d) com a hipnose. O que o perturbava sobremaneira não era apenas a eficácia duvidosa do procedimento, mas principalmente a confiabilidade das lembranças evocadas pelos sujeitos (Chertok \& Stengers, 1999). Isso porque havia sempre presente a perspectiva de que essas lembranças fossem frutos de mera sugestão ou da complacência dos sujeitos em relação a seus estimados médicos. Foi assim que a noção de um inconsciente independente que resiste ao outro ganhou um papel fundamental, pois ao mesmo tempo em que poderia resistir ao desejo e às sugestões do terapeuta, ele estaria além das intenções e da vontade dos próprios sujeitos, podendo até contrariar as expectativas de ambos (Chertok \& Stengers; Stengers, 2001). Desse modo, o inconsciente psicanalítico ganhava o estatuto de um legítimo objeto de estudo, podendo comparar o setting analítico a um laboratório clínico que, embora rompesse com a psicologia experimental em muitos aspectos, apresentava como esta a pretensão de um conhecimento confiável e superior aos demais. Sendo possível um acesso confiável e realista ao mundo psíquico além dos sintomas e aparências, seria possível também esperar um processo de cura mais efetivo e confiável, tal como o pretendia o cientista no que se refere ao controle dos fenômenos da natureza. Nessa perspectiva, podem ser encontradas, ao longo da obra de Freud (1905/ 1996b, 1912/1996c, 1917/1996d), importantes passagens que asseguravam a superioridade e oposição do método psicanalítico quanto aos métodos sugestivos.

Entretanto, o golpe de força consistiu em uma espécie de distanciamento sistemático quanto a questionamentos que poderiam ser subversivos ao edifício nascente da psicanálise. De um certo modo, a própria noção de transferência, que falava de um interjogo de forças com o inconsciente, poderia abrir questões incômodas no sentido de fazer ressaltar que o processo não se tratava simplesmente de uma revela- 
ção do mundo psíquico, mas de uma influência mútua que não deixava de lado seu parentesco com a sugestão (Chertok, 1989). Não é sem razões que alguns autores da reflexão pós-moderna (Gergen, 1996; McNamme \& Gergen, 1995/ 1998) fazem uma crítica acentuada à reprodução de discursos e narrativas que os clientes passam a fazer a partir de uma relação terapêutica, o que não deixa de recolocar em questão o problema da complacência. Ou seja, mesmo que as psicoterapias em geral possuam uma proposta realista elas não consistem em um laboratório, mas implicam em relações humanas onde não é possível escapar das influências e sugestões mútuas.

Contudo, esse não era o único ponto polêmico. Já ao final de sua vida, Freud (1937/1996f) destacou que as curas operadas pela psicanálise não seriam mais efetivas, duradouras e convincentes do que as de outros métodos. Isso não propiciou o mesmo impacto epistemológico do afã científico inicial e, em conseqüência, não permitiu que o problema da hipnose fosse revisitado. Embora o acesso privilegiado ao psíquico pretendido pela psicanálise fosse colocado sob suspeita, a maldição sobre a hipnose estava já lançada e a instituição psicanalítica dela dependia sobremaneira para se manter firme. Importava apenas que o Freud (1905/1996b) inicial da psicanálise se mantivesse vivo no seu projeto de desvendar de modo confiável e científico as profundezas do inconsciente, de tal modo que nem mesmo o fundador da psicanálise pudesse revisar certos pontos de suas próprias construções (Chertok \& Stengers, 1999).

Assim é possível perceber que o casamento entre a instituição psicanalítica e a noção de realidade foi decisivo para a compreensão da hipnose como processo terapêutico falho e objeto de estudo científico impossível. A hipnose era por demais ligada ao engano, à ilusão, ao incerto e ao fugidio das relações humanas, sem contar que seu parentesco histórico com o magnetismo e o espiritismo (Carroy, 1991; Meheust, 1999) pareciam transformar essa busca do real em um considerável pesadelo. Isso era bastante contrário à pretensão de acesso a uma realidade a-temporal, invariável e independente do contexto sócio-cultural, tal como rezava a vulgata da razão científica (Gonzalez Rey, 1996; Santos, 1987). Entretanto, esse mesmo tema impróprio consistia em uma denúncia contra o pensamento clínico nascente, que aspirando se submeter a esta razão, evitava o diálogo e as incômodas questões levantadas pela obra dos hipnotizadores. Assim, o que realmente importava não era apenas isolar esse tema impróprio, mas destiná-lo ao silêncio, situando-o em torno de preconceitos que desestimulassem os eventuais impulsos da própria curiosidade científica. A história da psicologia clínica precisava começar a ser escrita associada às luzes da razão e livre de quaisquer máculas.

\section{Alguns Começos Antes do Começo}

A atribuição do nascimento da psicologia a Wundt em 1879 (Marx \& Hillix, 1963/1978; Schultz \& Schultz; 1969/1981) traz uma questão importante sobre as relações dessa ciência com a hipnose. O que parece sugerir é que, enfim, a psicologia estaria ocupando um lugar de ci- ência, desvencilhando-se das heresias que poderiam abalar sua confiabilidade. A partir dessa data, boa parte das reflexões anteriores deveriam ser lançadas ao esquecimento ou ao título de curiosidade histórica, pois não poderiam contar com a confiabilidade dos métodos que buscavam agora embasar o projeto de uma psicologia enfim científica. Era uma vitória da racionalidade experimental, da vida de laboratório que finalmente poderia situar essa ciência como conhecimento válido na busca de acesso privilegiado ao real. No entanto, esse começo não deixava de ser contraditório até mesmo porque, reivindicando ser uma ciência enfim independente e com voz própria, a psicologia sempre esteve atrelada a outras ciências, como as ciências físicas, biológicas, sociais e humanas (Figueiredo \& Santi, 2002), o que a colocava na delicada posição da diversidade de escolas de pensamento (Neubern, 2001, 2003). Esse considerável mal estar foi ainda mais agudo em termos de psicologia clínica que, além da diversidade de abordagens, contava com um contex to de trabalho e um conjunto de objetos de estudo pouco afeitos à prova experimental. Embora não abdicasse do projeto científico e estivesse imbuída de sua racionalidade (Chertok \& Stengers, 1999; Neubern, 2001) o conhecimento clínico era, vez por outra, colocado sob suspeita a ponto de seus métodos serem considerados válidos apenas caso fossem restritos à prática clínica (Gonzalez Rey, 1996).

Todo esse cenário levou a conceber uma curiosidade que, em geral, passou desapercebida: é provável que essa ciência, que nasceu frágil e duvidosa, tenha tido necessidade de renegar sua própria história para que pudesse manter alguma credibilidade. Se é verdadeiro o fato de que Freud (1905/1996b) não negou a relação histórica entre hipnose e psicanálise e que, apesar dos problemas, continuou seu interesse especulativo pelo assunto em alguns momentos de sua obra (1921/1996e), não é menos verdadeiro que fez um considerável esforço para separar psicanálise e sugestão (1912/1996c), numa explícita oposição entre o conhecimento confiável e o duvidoso. Com isso deixaram de ser considerados outros importantes momentos da origem da psicologia que poderiam, mesmo hoje, leva-la a significativas releituras epistemológicas, históricas e clínicas.

É nesse sentido que se pode compreender uma das primeiras referências ao termo psicologia no pensamento moderno que remonta a Alexandre de Bertrand (1823, citado em Carroy, 1991) com a publicação do Traité du Somnambulisme. Nota-se que o jovem médico francês já apresentava um conjunto de concepções que remontavam a racionalidade ocidental e que justificaram o próprio nascimento de uma ciência psicológica, pois a medicina da época era insuficiente para a compreensão dos fenômenos magnéticos, hipnóticos e sonambúlicos. Rompendo com as noções mesmeristas, que preconizavam a ação de um fluído magnético nas curas, Bertrand se colocava na condição de um médico filósofo ou simplesmente psicólogo que buscava estudar a influência da imaginação nos processos terapêuticos, fossem eles somáticos ou psíquicos. Nesse ponto, seria possível 
considerar que aqui já constava o nascimento de uma ciência psicológica em moldes bastante similares à boa parte das linhas de pensamento atuais. A princípio, tratava-se de uma ciência que nasceu entre a medicina (natureza) e a filosofia (espírito), possuindo a perspectiva de um conhecimento novo que não se esgotasse em um desses lados.

Contudo, outro ponto que chama a atenção foi a própria tentativa de se desvencilhar do magnetismo, atribuindo à subjetividade humana, por meio da imaginação, um papel central na compreensão e efetivação da clínica. Vale destacar que a obra desse autor propiciou o desenvolvimento de reflexões e antagonismos teóricos de toda uma geração de pensadores na França do século XIX, como Maine de Biran (com a noção de um ser consciente e inconsciente e a comunicação entre corações), Taine (com a multiplicidade do eu e as alucinações) e Bergson (com a comunicação telepática) (Carroy, 1991, 1993 $)^{2}$. Todo esse movimento havia sido iniciado há mais de meio século antes de Wundt (citado em Schultz \& Schultz, 1969/1981) e Freud (Salomão, 1996), mas não ganhou relevo e reconhecimento como um ponto de origem da psicologia, provavelmente em função dos temas malditos que havia escolhido como objetos de estudo e reflexão. Ao mesmo tempo, boa parte dos autores acima se baseou em métodos clínicos, o que também poderia denunciar sua inconsistência em termos de exigências, principalmente devido ao valor dado ao método em termos de ciência (Demo, 1997). No entanto, caberia também questionar sobre os motivos dessa rejeição, posto que a maior parte das escolas clínicas atuais não se utilizam de métodos substancialmente distintos.

Esse afã científico ligado à hipnose também esteve presente numa das primeiras referências à psicoterapia que remonta a Hippolyte Bernheim (1891/1995) que a situou como um método sistemático e racional tendo como veículo principal as diferentes formas de sugestão. Ao longo de sua obra, esse autor sistematizou as aplicações clínicas da psicoterapia a diversos campos, como neuroses traumáticas, histerias, neuroses genitais, neurastenias, alcoolismo, nevralgias, reumatismo, dentre outros, ao mesmo tempo em que buscou teorizar sobre as formas de aceitação das sugestões pelo cérebro dos indivíduos. Embora reconhecesse sua dívida com os magnetizadores em termos de herança histórica e clínica, procurou desenvolver toda uma compreensão do processo hipnótico relacionando os tipos de sugestão com a atividade orgânica, principalmente do sistema nervoso central. Assim, seria possível compreender a psicoterapia como um processo que integrasse, de modo complexo, duas dimensões opostas na racionalidade ocidental: de um lado, a comunicação humana em suas diferentes nuances; de outro, os mecanismos cerebrais e orgânicos que poderiam transformar essas sugestões em processos de cura. Natureza e espírito estavam novamente sendo conciliados dentro de um projeto científico.

\footnotetext{
2 Vale lembrar que essa lista é bem mais ampla, incluindo ainda autores como Charcot e Janet (citados em Carroy, 1991). Deve-se destacar também que essa mesma época foi fértil em termos de organizações institucionais e criação de escolas (como as de Nancy e de Paris) para estudo e prática da hipnose.
}

O que pode ser destacado desse cenário é que a obra de Bernheim (1891/1995) foi caracterizada por uma dimensão que marcou todas as escolas de psicologia clínica: a tentativa de uma racionalidade científica. Entretanto, malgrado seu esforço de separação do já condenado magnetismo, as dimensões mais importantes de seu trabalho praticamente não deixaram suas marcas na história dessa ciência, até mesmo porque que esse autor é muito mais reconhecido como um antigo professor de Freud (1917/1996d) cujas concepções logo cederiam lugar a abordagens mais eficientes e racionais. Desse modo, o desinteresse dos psicólogos e médicos por sua obra talvez pudesse ser compreendido em torno de toda uma leitura institucional das comunidades científicas (Carroy, 1991; Chertok \& Stengers, 1999; Neubern, 2004), mas, ao que parece, acabou situado na lista de concepções que fracassaram na abordagem do real.

Nesse sentido, pode-se notar que a obra de muito desses autores foi pouco conhecida, estudada e problematizada pela grande maioria dos clínicos atuais, o que não impediu a criação dos mais diversos preconceitos sobre o tema. A compreensão da hipnose como um processo de submissão, ligado a um estado inconsciente e capaz de induzir os sujeitos a atos imorais parece ter perdurado até os dias atuais, embora tenha sido constantemente refutada por autores célebres do passado. Tal foi o caso de Joseph Delboeuf (1890/1993). Para ele a sugestão possuiria um papel importante no sentido de influenciar e transmitir importantes idéias aos indivíduos, mas, ao mesmo tempo, estes estariam dentro de uma certa consciência (le moi inconscient), onde não abandonariam o espírito crítico e a censura moral. Dito de outro modo, a hipnose não implicava em mero estado de passividade, mas em um estado onde o sujeito possuiria um papel ativo utilizando potenciais e recursos que habitualmente não estariam tão acessíveis. Assim, ao invés de um processo baseado na autoridade do médico e na passividade do paciente (Freud, 1905/1996b), a hipnose terapêutica implicava em um processo onde a participação do sujeito era fundamental, principalmente em termos da utilização desses recursos na lida com suas demandas. Seria redundante, neste ponto, ressaltar a proximidade dessa idéia quanto às idéias atuais de boa parte das escolas de psicoterapia, onde o sujeito, através do acesso a seus potenciais, é ator no processo terapêutico (Anderson \& Goolishian, 1993). Outra contribuição interessante desse autor foi a respeito da própria noção de relação terapêutica, particularmente por conceber que o terapeuta também receberia considerável influência do sujeito por ele hipnotizado. Mas, ao mesmo tempo, Delboeuf (1890/1993) destacou que esse processo de influência permitiria a construção de settings essencialmente distintos, o que poderia explicar as diferenças de pacientes e fenômenos entre as diferentes escolas de hipnotismo da época, como a de Nancy e de Paris. No entanto, sua obra não impediu que sobre a hipnose fossem impregnados os estigmas da submissão à autoridade do terapeuta e do sujeito alheio ao processo terapêutico. Ela talvez tenha sido considerada como subversiva em demasia, principalmente devido a suas noções de influência e suas implicações críticas ao realismo dominante. 
Esse conjunto de semelhanças entre as escolas clínicas vigentes e as do passado levam a uma reflexão contundente e pesarosa, segundo a qual na história da ciência muitas vezes todo o esforço por reconhecimento pode ser inútil quando uma maldição já está lançada. Os hipnotizadores do passado, como os clínicos do último século, buscaram associar-se ao paradigma dominante, expulsar os mitos, conferir um caráter de ciência a suas construções e organizar-se institucionalmente (Carroy, 1991; Chertok, 1989). Ambos sofreram com as críticas de escolas rivais e até de outras ciências, que, entre o sarcasmo e a convicção, colocaram em dúvida a cientificidade de suas propostas. Mas sob os hipnotizadores pesavam outros fardos: a ruptura que a hipnose efetivava quanto ao princípio do conhecimento de uma realidade perene e sólida consistia na condenação de todas as medidas que pudessem ser feitas em nome da ciência, como também alimentava os mais diversos preconceitos e estigmas sobre a mesma. A diferença talvez tenha sido a de que enquanto os clínicos tiveram condições de fazer um acordo pouco convincente com essa realidade, aos hipnotizadores não foi possível sequer uma negociação nesse sentido.

\section{A Retomada de um Conhecimento sem Respostas}

Uma questão curiosa na história da hipnose é que, mesmo sem atender as exigências da cientificidade, ela sempre foi marcada pela eficiência terapêutica de suas abordagens por meio da obra dos mais distintos autores em diferentes épocas ${ }^{3}$ (Melchior, 1998). Mesmo não sendo convincente quanto à sua abordagem do real, seria possível comparar seu poder de promover mudanças com uma das principais pretensões da ciência moderna - a transformação da natureza - mas sem o conhecimento preciso promovido pelo método científico e sem os princípios da predição e do controle dos fenômenos. A própria posição de Freud, duvidando de sua eficiência, pode ser revista nesse sentido quando se considera seu desconforto e suas noções equivocadas quanto ao uso da técnica (Castilho, 2002; Chertok, 1989). O que faltava para a hipnose era justamente a obediência que lhe permitisse se transformar em um objeto domesticado, capaz de aceitar as imposições do laboratório ou do setting clínico, malgrado as precariedades de ambos para atender suas exigências (Stengers, 2001).

Entretanto, o século XX foi marcado por inúmeras transformações epistemológicas que, provavelmente, permitiram um resgate da hipnose enquanto tema de reflexão e prática clínica. Em termos de paradigma científico, houve uma espécie de retomada de noções que, de uma posição marginal, passaram a co-habitar com as perspectivas já consagradas e dominantes. Assim, a criação, evocando o antigo livre-arbítrio, passou a conviver mais de

\footnotetext{
${ }^{3} \mathrm{O}$ que pode ser verificado de Puységur (1785/2003), passando por Bernheim (1891/1995) e Delboeuf (1890/1993) a Milton Erickson (Erickson \& Rossi, 1980), François Roustang (1991, citados em Melchior, 1998), dentre outros.
}

perto com a determinação, enquanto o local e singular passaram a fazer frente ao universalismo; a história ganhou terreno junto à eternidade, como também a desordem, a incerteza e o acidente colocaram em cheque as concepções do universo como um relógio perfeito (Santos, 1987). O objeto não pode mais ser concebido sem o sujeito, ao mesmo tempo em que suas fronteiras se tornaram difusas e cederam lugar a um conjunto de conexões que o integram ao contex to e ao tempo. Nessa perspectiva, enquanto a realidade deixou de ser um conjunto de objetos sólidos e definidos, para se constituir em um universo de partículas que retroagem em movimentos complexos, o conhecimento científico passou a incorporar noções antes proscritas como o sujeito, a conexão, a probabilidade, a complexidade, a incerteza e a incompletude (Demo, 1997; Morin, 1990; Stengers, 1995). De um modo geral, é como se houvesse um reconhecimento de que a pretensão de um saber definitivo e absoluto da realidade nunca tenha sido uma questão de realidade, mas de utopia humana. Não é sem razões que esse mesmo século também foi muito fecundo quanto à discussão da dimensão social da ciência no sentido de que sua compreensão não poderia passar distanciada dos processos comuns a uma comunidade científica ${ }^{4}(K u h n, 1970 / 1996$; Morin, 1991; Santos, 1989; Stengers, 1995).

Em meio a esse conjunto de rupturas e subversões, a discussão sobre a hipnose foi inicialmente retomada em termos clínicos, principalmente a partir da obra de Milton H. Erickson ${ }^{5}$ (Erickson \& Rossi, 1980). De certo ponto de vista, essa retomada não apresenta muitas diferenças quanto a alguns de seus ancestrais do magnetismo e da hipnose, pois há uma preocupação explícita com a construção de processos terapêuticos eficientes, uma crítica incisiva quanto às possibilidades da racionalidade científica na abordagem desses fenômenos e um conjunto de medidas rumo a uma institucionalização do movimento ${ }^{6}$. Entretanto, de um ponto de vista epistemológico, a obra de Erickson apresenta estreita sintonia com a retomada de noções marginais próprias da crise de paradigma atual (Neubern, 2002), o que talvez possa aproximá-lo, de alguma forma, de concepções hoje discutidas no panorama científico. A princípio, há uma crítica contundente quanto aos pressupostos tradicionais para a construção de uma teoria, pois a generalização e o universalismo que lhes são próprios seriam excludentes com relação à singularidade dos sujeitos, o que esse autor considerava fundamental para a clínica (Erickson \& Rossi, 1979; Zeig, 1985/1997). De modo

\footnotetext{
* Isso não implica necessariamente em uma postura construcionista (Gergen, 1996) que se coloca como ontologicamente muda, mas na importância do reconhecimento dos processos intersubjetivos na invenção - descoberta da objetividade (Stengers, 1995, 1999).

${ }^{5}$ Considerado por certos autores (Bellet, 1992; Melchior, 1998; Zeig, 1985/ 1997) como o pai da hipnose moderna.

${ }^{6}$ Erickson foi um dos fundadores da Sociedade Americana de Hipnose Clínica e do American Journal of Clinical Hypnosis. Atualmente a abordagem ericksoniana é um dos movimentos de psicoterapia que mais cresce no mundo (Robles, 1997/2000).
} 
similar, sua visão de homem ${ }^{7}$ estaria muito mais próxima de uma subjetividade sistêmica e complexa do que das visões tradicionais de objeto de estudo, uma vez que sustentavam a singularidade e as configurações do momento sem se fixarem em conteúdos e etiologias determinadas $a$ priori (Neubern, 2002, 2004). Os problemas dos sujeitos não deveriam ser compreendidos de antemão em função de um conteúdo ou de uma dimensão específica, como o passado, mas em função do conjunto de arranjos próprios de seu cenário subjetivo naquele momento.

Em meio a essa visão de homem e de mundo fluida e mutável, pode-se considerar que esse autor não possuía a intenção de associar hipnose e verdade, como se aquela se constituísse em um método privilegiado de acesso a esta (Neubern, 2002, 2004; O'Hanlon, 1987/1994). A complexidade da subjetividade exigiria um conhecimento dinâmico, com conclusões bastante parciais e locais e com um fim pragmático no sentido de levar antes ao desencadeamento de processos do que ao conhecimento ou a confirmação de uma lei ou hipótese. A hipnose, nesse sentido, não estaria associada fielmente à necessidade da explicação objetiva $\mathrm{e}$ etiológica, mas a um processo que envolvesse sentidos, padrões e necessidades configurados de modo complexo e próprio ao sujeito, obedecendo a uma organização local (ao invés de universal) e mutável em alguns de seus momentos. Assim, não seria possível esperar que sua obra pudesse desembocar na fabricação de alguns dos arcabouços próprios do paradigma dominante, como por exemplo, a construção de uma teoria de personalidade, embora seja possível considerar que, segundo esse mesmo paradigma, ela possa assumir um caráter eminentemente técnico.

Essas considerações trazem à tona as reflexões contundentes que a hipnose sempre trouxe para a psicologia clínica (Stengers, 2001). Sua prática permite conceber que é possível lidar com a mente para transformá-la, sem, contudo, conhece-la segundo as exigências científicas. De um certo modo, essa retomada da hipnose por meio de Milton Erickson (Erickson \& Rossi, 1979, 1980) parece retomar a angustiante idéia de que nada mudou, uma vez que ela se constitui em um conhecimento que não traz respostas e que não explica, apesar de sua eficiência clínica e dos espaços institucionais que conquista aos poucos em vários países. Entretanto, mesmo sem respostas, a hipnose é retomada em um outro contex to, um cenário distinto de sua época de nascimento, onde o próprio conhecimento científico é revisto e passa por grandes transformações.

Isso leva a conceber que sua importância se dá, não pelas respostas que deixa de trazer, mas pelas perguntas que leva a pensar em diferentes níveis sobre a pretensão de se construir uma psicologia científica (Neubern, 2004; Stengers, 200 1). A hipnose, ligada a todo um processo de influência e sugestão, não satisfaria as exigências científicas ou seria o

\footnotetext{
${ }^{7}$ É importante ressaltar que Erickson jamais sistematizou suas idéias nesse sentido. Essas reflexões partem de outros autores (Melchior, 1998; Neubern, 2002, 2004 e O'Hanlon, 1987/1994) que associam suas contribuições com as reflexões atuais.
}

próprio conhecimento científico quem deveria ser revisado e transformado para o estudo da subjetividade humana? A ruptura que ela implica em termos da separação sujeito e objeto $^{8}$ deveria ser compreendida como um obstáculo ou como apelo a uma nova racionalidade? Quais deveriam ser as condições epistemológicas que uma teoria deveria obedecer para a explicação dos processos subjetivos e hipnóticos? A que condições deveriam obedecer a explicação e a generalização nesse sentido? O tipo de resposta que essas questões receberão ainda está por ser conhecido. Contudo, é importante que essas reflexões sejam levadas a cabo, principalmente em nome do reconhecimento de um tema que justificou uma das origens da psicologia (Carroy, 1991) e que certamente tem muito a dizer sobre seu porvir. $\mathrm{O}$ que ficou marcado pela hipnose até o momento é uma transformação que não se permite ser conhecida, que parece jogar com a ciência apontando suas limitações sem se permitir apreender. Mas o que a retomada desse tema neste justo momento parece sugerir é que talvez seja o próprio conhecimento que necessite de mais profundas transformações para poder compreender e explicar esse processo tão altamente implicado com a subjetividade humana.

\section{Conclusão: Por um Conhecimento com Auto-Conhecimento}

A linha de reflexão desenvolvida até aqui permite uma analogia entre a situação epistemológica da psicologia clínica quanto à hipnose e a de um paciente que se submete a uma psicoterapia. Neste caso específico, é muito comum que o trabalho seja conduzido enfocando algumas questões do passado do sujeito que ainda permanecem vivas em sua subjetividade e suas ações sociais e que com freqüência lhe trazem algum tipo de limitação ou sofrimento. Entretanto, essa investigação do passado não consiste em um simples apelo explicativo, mas possui um intento pragmático de auxiliar o sujeito na reconstrução de significados e sentidos de dimensões importantes de sua vida, a começar por sua própria identidade (Gonzalez Rey, 1997; Grandesso, 2000; Mahoney, 1991). Com o andamento da terapia, não é apenas o passado que ganha novos sentidos, mas a própria relação do sujeito consigo, com seus momentos atuais e suas projeções futuras.

Essa analogia, por sua vez, parece trazer contradições bastante incômodas, pois seguindo as inspirações da ciência moderna (Demo, 1997; McNamme \& Gergen, 1995/1998), a psicologia clínica coloca-se como um conhecimento sem auto-conhecimento, um conhecimento que se pensa pouco e está muito mais preocupado em desvendar o mundo que a si mesmo. O que os psicólogos clínicos propõem diariamente a seus pacientes em suas práticas não poderia ser pensado e proposto, em termos epistemológicos, para seus próprios conhecimentos teóricos. Essa afirmação não visa dizer que a psicologia clínica atualmente não tenha buscado esse tipo

\footnotetext{
${ }^{8}$ No sentido de que toda teoria hipnótica é hipnogência, isto é, ela anuncia o que vai produzir (Stengers, 2001). Daí a idéia do efeito Rosenthal (Melchior, 1998) e da sugestão sempre presente nas relações humanas e psicoterapias (Chertok, 1989)
} 
de reflexão, mas que essa tarefa está atrasada (Gonzalez Rey, 1997) e ainda não pôde contemplar temas cruciais de sua própria história. Nesse sentido, a hipnose implica em uma considerável contradição, posto que, possuindo uma grande importância histórica, clínica e epistemológica para a psicologia clínica deveria ser atentamente investigada e problematizada para que a história dessa ciência fosse contada de outra forma, o que, sem dúvidas, poderia apontar caminhos bastante interessantes para sua transformação. Contudo, o que se pode notar atualmente é que a hipnose permanece interditada por um verdadeiro recalque epistemológico que a impede de tomar parte nessa história, como se a sua simples presença pudesse implicar no proibido e no herético em termos de razão, ciência e terapia.

É possível que a conseqüência mais pungente e problemática desse recalque sejam as barreiras que se criaram para que a psicologia clínica pudesse responder a uma questão fundamental, proferida em termos de identidade científica, que remonta à própria tradição clássica: quem sou eu? $D e$ onde vim? Para onde vou? (Neubern, 2004). Não é sem razões que sua associação à racionalidade científica tenha ocorrido dentro de um considerável mal estar, sendo por vezes tida como um ramo menos científico (e, portanto, mais duvidoso) da psicologia, como o ramo onde a psique não teria sido totalmente exorcizada do subjetivo (Gonzalez Rey, 1996; Neubern, 2003). Em outras palavras, mesmo tendo sido obrigada a negar sua própria história, onde a hipnose não foi um mero acidente, a psicologia clínica não conseguiu um sucesso integral quanto às exigências científicas, como se tivesse permanecido a meio caminho de atingi-las ${ }^{9}$. Embora tenha conquistado espaços sociais e institucionais e tenha acabado por ser reconhecida como um tipo de ciência, o silêncio imposto sobre sua própria história não impediu sua angústia epistemológica.

Diante dos problemas práticos da própria clínica freqüentemente puderam ser constatadas dúvidas constrangedoras basicamente em dois sentidos. Por um lado, se as possíveis soluções e reflexões devessem ser buscadas a partir da racionalidade científica, haveria um acordo com o projeto de ciência, mas um incômodo nada desprezível quanto à própria compreensão de um objeto de estudo substancialmente distinto dos objetos relacionados ao método científico tradicional. Essa primeira solução de compromisso, que não deixou de se constituir em um verdadeiro pesadelo, talvez tenha tido como uma das principais aliadas o uso da força institucional que mutilou objetos de estudo em sua complexidade e adequou as teorias a noções universalistas e reificadas (Gonzalez Rey, 1997; McNamme \& Gergen, 1995/1998; Neubern, 2001). Mas, por outro lado, a segunda possibilidade - a de uma racionalidade distinta, envolvendo noções próprias ao universo subjetivo - desembocou, por vezes, em um amplo silêncio, pois não poderia existir outra forma de pensar as origens da psicologia que não

\footnotetext{
9 Neubern (2003) compara, analogicamente, a psicologia como a filha bastarda do paradigma dominante, por se tratar de um conhecimento que acaba sendo reconhecido como ciência, mas com reservas.
}

fosse por meio das referências já oficializadas e comprometidas com o ideal científico, como no caso de Freud (Chertok \& Stengers, 1999). Não seria nada simples buscar soluções e reflexões em termos de algo mais original, pois o próprio universo da subjetividade já havia sofrido um considerável processo de colonização por parte da racionalidade científica (Santos, 2000) ${ }^{10}$. Em suma, nesse caso específico o projeto de ciência foi, desde o início, inconciliável com sua própria história.

Diante de todo esse quadro, pode-se indagar qual seria a pertinência para a psicologia clínica de se voltar à reflexão sobre a hipnose. Por que seria importante retornar a um tema que parece apresentar muito mais perguntas do que respostas e cujo progresso em termos de conhecimento foi praticamente irrisório nos últimos duzentos anos (Stengers, 2001)? Por que seria importante recontar uma história se já existem histórias? Em que a psicologia clínica poderia enriquecer fazendo esse tipo de reflexão? As respostas a esse tipo de questão podem ser variadas, mas no escopo desse artigo, podem ser destacados dois pontos ligando a perspectiva da relação entre clínica e ciência sobre os quais a hipnose incide arduamente.

O primeiro deles é a crítica que ela proporciona à perspectiva de um acesso privilegiado e isomórfico ao real, que se constituiu em um dos pilares centrais não só do projeto científico, como das escolas modernas de psicologia clínica (Gonzalez Rey, 1997; Mahoney, 1991; McNamme \& Gergen, 1995/1998). O que a hipnose parece mostrar nesse sentido, é uma subjetividade humana permeada por processos fugidios, nebulosos e por vezes mutáveis, por processos míticos e simbólicos que remetem diretamente a seu contex to de geração, como também por toda a cultura que perpassa esse contexto e a vida dos sujeitos nele implicados. Mas ela os mostra dentro de uma ótica que carece de confiabilidade tradicional, que não se adequa a pareceres definitivos e controlados e parecem sugerir uma realidade muito mais complexa que a realidade perene do paradigma dominante, por ser marcada pela influência mútua, pela criação, pelo ilusório e pelo passageiro. Esse primeiro ponto de reflexão sugere que essa ausência de confiabilidade trazida à tona pela hipnose é integrante constituinte da subjetividade humana e que por isso não deve ser desprezado sob o pretex to de sua inadequação científica, como o fez Freud em sua busca pelo definitivo (Chertok \& Stengers, 1999). A consequiência mais imediata nesse sentido é um forte apelo a uma nova racionalidade, a um novo paradigma científico em que a noção de realidade seja colocada sob questão e as noções anteriormente marginais ganhem um novo espaço ${ }^{11}$.

\footnotetext{
${ }^{10}$ Para Santos (2000) o paradigma ocidental promoveu a divisão entre o conhecimento científico (com métodos e concepções objetivas) e os demais tipos de conhecimento (próprios do universo subjetivo). Entretanto, após se firmar como conhecimento privilegiado, a racionalidade científica buscou também se impor aos outros conhecimentos (como filosofia, direito, artes, literatura) o que caracterizou um verdadeiro processo de colonização.

${ }^{11}$ Veja-se, por exemplo, a proposta construtivista de Melchior (1998), o problema da influência debatido por Borc-Jacobsen (2001) e as reflexões sobre a complexidade de Neubern (2004).
} 
Já o segundo ponto refere-se à própria dimensão institucional da psicologia clínica, mais especificamente à necessidade de uma concepção reflexiva sobre as ações dos sujeitos na atribuição de sentido a suas práticas. Um dos aspectos que chama muito a atenção nesse processo é que a história passou a ser contada em nome de um triunfo do real, sem que fossem levantados os vários processos de oposição e conflito que diversos grupos e instituições moveram contra e a favor do reconhecimento da hipnose (Carroy, 1991; Chertok \& Stengers, 1999; Meheust, 1999). Em outros termos, ao mesmo tempo em que se apresentou uma concepção de realidade confiável, esconderam-se os atores que, mais que seus descobridores, foram seus artífices. Seguindo à perspectiva dominante, eles deveriam ser mantidos na conta de simples reveladores da realidade psíquica humana para que a aliança com o paradigma científico fosse efetivada. Assim, torna-se necessário que as práticas sociais no interior da psicologia clínica sejam repensadas principalmente em termos de conceber que os sujeitos e instituições possuem um papel ativo na construção de sentido da realidade com a qual dialogam (Gergen, 1996; Gonzalez Rey, 1997; Neubern, 2004). Essa tarefa não é simples na medida em que o realismo ingênuo que visa desvendar o mundo sem se pensar, mesmo que discutido e criticado epistemologicamente, ainda é bastante presente nas comunidades dos psicólogos clínicos.

O que talvez a hipnose traga de mais interessante nesse sentido, é que ela faz uma relação direta entre seu contex to de geração e seus produtos ao conceber que toda teoria hipnótica é hipnogênica, ou seja, ela gera aquilo que ela mesma anuncia (Melchior, 1998; Stengers, 2001). Essa perspectiva cria efetivamente um grave problema para a psicologia clínica particularmente pelas barreiras epistemológicas que parece romper, a começar por situar a reflexividade como um processo obrigatório, um processo que se coloque questões sobre seu contex to de surgimento e sobre as retroações que existem entre os diferentes sujeitos que dele participam. Entretanto, a hipnose parece levar a pensar um pouco além, tocando de modo inevitável em duas questões cruciais. Se, em sua prática, as ações humanas geram aquilo que anunciam torna-se obrigatória a reflexão sobre os pressupostos, valores e concepções implícitos nessa geração, como também sobre as conseqüências pragmáticas de seus resultados. Trata-se aqui de um problema de responsabilidade ética não só com os sujeitos, mas com o próprio conhecimento que é criador de realidades ou que, ao menos, participa ativamente nessa criação.

Ela não permite que se espere uma simples revelação do real, mas convida a uma incursão crítica sobre os pressupostos que antecedem sua construção, o que consiste em uma tarefa árdua em termos individuais e institucionais. Por outro lado, esse retorno reflexivo remete ainda a uma questão de utopia, principalmente por abrir a possibilidade de colocar os sujeitos em uma posição com relativa possibilidade de escolha e autonomia na construção desse conhecimento. Há aqui um problema epistemológico profundo, pois a própria racionalidade dominante sempre o colocou na posição de revelador de uma realidade inexorável da qual apenas seria possível sofrer as conseqüências. Se essa utopia remetesse a reflexividade e a possíveis escolhas talvez fosse possível conceber um conhecimento e uma realidade que se pretende e se deseja, ao invés de simplesmente permanecer na postura de sofrer suas conseqüências ${ }^{12}$. Evidentemente, esse ponto é polêmico e abre debates os mais diversos, inclusive pelo fato de atingir tanto o pressuposto realista como o da separação entre conhecimento e realidade. Porém, o que se pode conceber agora é que a retomada da hipnose está apenas começando e que, portanto, essas questões ainda estão em aberto.

\section{Referências}

Anderson, A., \& Goolishian, H. (1993). O cliente é o especialista. Nova Perspectiva Sistêmica, 3, 8 - 24.

Bellet, P. (1992). L'Hypnose. Paris: Odile-Jacob.

Bernheim, H. (1995). Hypnose, suggestion et psychothérapie. Paris: Fayard. (Original publicado em 1891)

Borc-Jacobsen, M., \& Dufresne, T. (2001). Rétour à Delboeuf? Ethnopsy, 3, $69-88$.

Carroy, J. (1991). Hypnose, suggestion et psychologie. L'Invention du sujet. Paris: Puf.

Carroy, J. (1993). Magnétisme, hypnose et philosophie. In I. Stengers (Ed.), Importance de l'hypnose (pp. 169 - 192). Paris: Le Plessis-Robinson.

Castilho, J. (2002). A vida e a técnica de Sigmund Freud: As bases para a psicanálise infantil. Dissertação de Mestrado nãopublicada, Programa de Pós-Graduação em Psicologia Clínica, Universidade de Brasília, DF.

Chertok, L. (1989). Hypnose et suggestion. Paris: Puf.

Chertok, L., \& Stengers, I. (1999). La blessure narcissique. Paris: Le Plessis Robinson.

Delboeuf, J. (1993). Le magnétisme animal. À propos d'une visite à l'Ecole de Nancy. Paris: Fayard. (Original publicado em 1890) Demo, P. (1997). Conhecimento moderno. Petrópolis, RJ: Vozes.

Erickson, M., \& Rossi, E. (1979). Hypnotherapy: An exploratory casebook. New York: Irvington.

Erickson, M., \& Rossi, E. (1980). The collected papers of Milton H. Erickson, MD. New York: Irvington.

Figueiredo, L. (1992). A invenção do psicológico. São Paulo, SP: Escuta.

Figueiredo, L., \& Santi, P. (2002). Psicologia: Uma nova (re) introdução. São Paulo, SP: Editora da Pontifícia Universidade Católica de São Paulo.

Freud, S. (1996a). Artigos sobre hipnotismo e sugestão. (J. O Aguiar Abreu, Trad.). In J. Salomão (Ed.), Edição standard das obras psicológicas completas de Sigmund Freud: Vol. 1 (pp. $111-$ 120). Rio de Janeiro, RJ: Imago. (Original publicado em 18881892)

Freud, S. (1996b). Sobre a psicoterapia (J. O Aguiar Abreu, Trad.). In J. Salomão (Ed.), Edição standard das obras psicológicas completas de Sigmund Freud: Vol. 7 (pp. 239-251). Rio de Janeiro, RJ: Imago. (Original publicado em 1905)

\footnotetext{
${ }^{12}$ Essa "pretensão" e esse "desejo" não devem ser concebidos como mera construção social, como se toda realidade e ontologia se esgotasse nessa construção Embora essa questão tenha sido pouco explorada em termos da hipnose (Stengers, 2001), ela pode ser concebida em termos da ciência em geral (Stengers, 1999) e da própria psicologia (Gonzalez Rey, 1997; Mahoney, 1991; Neubern, 2004).
} 
Freud, S. (1996c). Recomendações aos médicos que exercem a psicanálise (J. O Aguiar Abreu, Trad.). In J. Salomão (Ed.), Edição standard das obras psicológicas completas de Sigmund Freud: Vol. 12 (pp. 147-162). Rio de Janeiro, RJ: Imago. (Original publicado em 1912)

Freud, S. (1996d). A terapia analítica. (J. O Aguiar Abreu, Trad.). In J. Salomão (Ed.), Edição standard das obras psicológicas completas de Sigmund Freud: Vol. 16 (pp. 523-539). Rio de Janeiro, RJ: Imago. (Original publicado em 1917)

Freud, S. (1996e). Psicologia de grupo e análise do ego (J. O Aguiar Abreu, Trad.). In J. Salomão (Ed.), Edição standard das obras psicológicas completas de Sigmund Freud: Vol. 18 (pp. 89183). Rio de Janeiro, RJ: Imago. (Original publicado em 1921)

Freud, S. (1996f). Análise terminável e interminável (J. O Aguiar Abreu, Trad.). In J. Salomão (Ed.), Edição standard das obras psicológicas completas de Sigmund Freud: Vol. 23 (pp. 247-287). Rio de Janeiro, RJ: Imago. (Original publicado em 1937)

Gergen, K. (1996). Realidad y relaciones. Barcelona, España: Paidós.

Gonzalez Rey, F. (1996). Problemas epistemológicos de la psicologia. La Habana, Cuba: Academia.

Gonzalez Rey, F. (1997). Epistemología qualitativa y subjetividade. La Habana, Cuba: Pueblo y Educacion.

Grandesso, M. (2000). Sobre a reconstrução do significado. São Paulo, SP: Casa do Psicólogo.

Kuhn, T. (1996). A estrutura das revoluções científicas (B. Boeira \& N. Boeira, Trad.). São Paulo, SP: Perspectiva. (Original publicado em 1970)

Levy, A (1997). Sciences cliniques et organizations sociales. Paris: Puf.

Mahoney, M. (1991). Human change process. New York: Basic Books.

Marx, M., \& Hillix, W. (1978). Sistemas e teorias em Psicologia (A Cabral, Trad.). São Paulo, SP: Cultrix. (Original publicado em 1963)

McNamme, S., \& Gergen, K. (Ed.). (1998). A terapia como construção social (C. Dornelles, Trad.). Porto Alegre, RS: Artes Médicas. (Original publicado em 1995)

Meheust, B. (1999). Somnambulisme et médiumnité. Paris: Synthelabo.

Melchior, T. (1998). Créer le réel. Hypnose et thérapie. Paris: Seuil. Morin, E. (1990). Science avec conscience. Paris: Seuil.

Morin, E. (1991). La méthode IV. Les idées. Paris: Seuil.
Neubern, M. (2001). Três obstáculos epistemológicos para o reconhecimento da subjetividade na psicologia clínica. Psicologia: Reflexão e Crítica, 14(1), 242-252.

Neubern, M. (2002). Milton Erickson e o cavalo de tróia: A terapia não convencional no cenário da crise dos paradigmas em psicologia clínica. Psicologia: Reflexão e Crítica, 15(2), 363-372.

Neubern, M. (2003). La psychologie clinique: Du malaise aux possibilités épistémologiques, Psychothérapies, 23(2), 81-88.

Neubern, M. (2004). Complexidade e psicologia clínica: Desafios epistemológicos. Brasília, DF: Plano.

O'Hanlon, W. (1994). Raízes profundas. Fundamentos da terapia e da hipnose de Milton Erickson. (J. P. Santos, Trad.). Campinas, SP: Psy II. (Original publicado em 1987)

Puységur, A. M. J. C (2003). Mémoires pour servir à l'histoire et à l'établissement du magnétisme animal. Paris: Imago. (Original publicado em 1785).

Robles, T. (2000). Um seminário ericksoniano com Jeffrey Zeig (A M. Machado \& E. C. Alves Pinto, Trad.). Belo Horizonte, MG: Diamante. (Original publicado em 1997)

Salomão, J. (Ed.). (1996). (J. O Aguiar Abreu, Trad.). Edição standard das obras psicológicas completas de Sigmund Freud: Vols. 1-23. Rio de Janeiro, RJ: Imago.

Santos, B. (1987). Um discurso sobre as ciências. Porto, Portugal: Afrontamento.

Santos, B. (1989). Introdução a uma ciência pós-moderna. São Paulo, SP: Graal.

Santos, B. (2000). Crítica da razão indolente. São Paulo, SP: Cortez.

Schultz, D., \& Schultz, S. (1981). História da Psicologia moderna (A U. Sobral \& M. S. Gonçalves, Trad.). São Paulo, SP: Cultrix. (Original publicado em 1969)

Stengers, I. (1995). L'Invention des sciences modernes. Paris: Synthelabo.

Stengers, I. (1999). Pour en finir avec la tolérance. Cosmopolitiques 7. Paris: La Découverte.

Stengers, I. (2001). Qu'est-ce que l'hypnose nous oblige à penser. Ethnopsy, 3, 13-68.

Yapko, M. (1992). Hypnosis and the treatment of depressions. New York: Brunner.

Zeig, J. (1997). Vivenciando Erickson (R. Montibeller \& J. C. V. Gomes, Trad.). Campinas, SP: Psy II. (Original publicado em 1985)

Recebido: 25/08/2004 $1^{a}$ revisão: 15/03/2005 Aceite final: 16/09/2005 